\title{
Religious/spiritual concerns of patients with brain cancer and their caregivers
}

\author{
Petra J. Sprik ${ }^{\wedge}$, Beba Tata ${ }^{2}$, Brian Kelly ${ }^{3}$, George Fitchett ${ }^{4}$ \\ ${ }^{1}$ Levine Cancer Institute, Charlotte, NC, USA; ${ }^{2}$ Mayo Clinic, Rochester, MN, USA; ${ }^{3}$ David H. Koch Center for Cancer Care, Memorial Sloan \\ Kettering Cancer Center, New York, NY, USA; ${ }^{4}$ Rush University Medical Center, Chicago, IL, USA \\ Contributions: (I) Conception and design: All authors; (II) Administrative support: None; (III) Provision of study materials or patients: None; (IV) \\ Collection and assembly of data: None; (V) Data analysis and interpretation: None; (VI) Manuscript writing: All authors; (VII) Final approval of \\ manuscript: All authors. \\ Correspondence to: Petra J. Sprik. Levine Cancer Institute, 1021 Morehead Medical Dr., Charlotte, NC 28204, USA. Email: Petra.Sprik@atriumhealth.org.
}

\begin{abstract}
Research conducted over the last 20 years supports that many patients with cancer engage religion and spirituality (R/S) when coping with their illness. Research on patients with brain cancer is more minimal but mirrors the same findings. This article provides a brief overview of the research about R/ $\mathrm{S}$ and coping among cancer patients, then summarizes the research about R/S among patients with brain cancer and their caregivers. The following topics are discussed: (I) the importance of R/S to patients with brain cancer and their caregivers, (II) specific R/S needs experienced by patients with brain cancer and their caregivers over the cancer continuum, (III) R/S coping mechanisms engaged by brain cancer patients and their caregivers, and (IV) the healthcare systems' engagement of R/S needs within the healthcare setting. This is followed by professional chaplains' descriptions of their own experience with R/S concerns of patients with brain cancer and their caregivers, and the spiritual care they have offered them. Hear My Voice, a new spiritual life review intervention, is described. Research to deepen understanding of the R/S concerns of patients with brain cancer and their loved ones, and spiritual care interventions offered to them is recommended.
\end{abstract}

Keywords! Brain cancer; brain neoplasms; caregivers; chaplains; spiritual care

Submitted Mar 26, 2020. Accepted for publication Aug 11, 2020.

doi: 10.21037/apm-20-813

View this article at: http://dx.doi.org/10.21037/apm-20-813

\section{Religion/spirituality of cancer patients}

Over the past 20 years a substantial body of research about religion and spirituality (R/S) and coping with cancer has emerged (1-4). Large majorities of cancer patients cite R/ $\mathrm{S}$ as one of the most important factors that helps them cope with their illness (5). Religious activities are important for many cancer patients. Among 700 newly diagnosed patients, over three-fourths reported the use of prayer (6). Further, a large meta-analysis has shown positive associations between $\mathrm{R} / \mathrm{S}$ and measures of physical, emotional and social health
(7-9). Other studies have shown that as many as $50 \%$ of cancer patients experience some R/S struggle, pain or distress and that R/S distress is consistently associated with poorer emotional well-being and quality of life (10-12). Research also shows that most cancer patients welcome inquiry about $\mathrm{R} / \mathrm{S}$ concerns from their health professionals (13) and they welcome spiritual care providers (chaplains) as part of their healthcare team (14). There is also evidence of lower ratings of the quality of care and satisfaction with care when R/S needs are not addressed (15).

$\wedge$ ORCID: 0000-0003-3097-5995. 


\section{Religion/spirituality of patients with brain cancer}

\section{Importance of religion/spirituality}

Compared to some other types of cancer (e.g., breast, prostate), there has been less research about R/S and coping among patients with brain cancer. While this research is more modest, its themes mirror those in the cancer literature in general. Patients with brain cancer may be particularly vulnerable to $\mathrm{R} / \mathrm{S}$ needs due to the high risk of mortality and risk for loss of personality/self that accompany changes in cognitive and functional status associated with disease progression (16). One caregiver of a patient with brain cancer said, "It's not just a diagnosis, it's almost like it's a life sentence on all the other aspects of his life" [(16), p. 4]. Up to $70 \%$ of neuro-oncology patients describe $\mathrm{R} / \mathrm{S}$ as helpful during their disease experience $(16,17)$. Compared to those with higher levels of education, patients and caregivers with lower education ranked R/S needs more highly (18). For some neuro-oncology patients $\mathrm{R} / \mathrm{S}$ can intensify over the course of their disease (19-21) while for others it remains stable (22). R/S needs may be particularly salient for brain cancer patients and their caregivers prior to confirmation of malignancy (20).

\section{Religious/spiritual needs}

Different types of R/S needs have been described in the literature. Several studies describe patients exploring meaning in life as they deal with brain cancers $(16,21,23,24)$, especially among patients with a strong desire for coherence (23). This can involve learning life lessons from the challenges one is facing (16), reflecting on life to assess the difference one made (21), and planning to live life with more meaning $(21,23,24)$. Other research describes patients reappraising their values (23), including an increased focus on qualityof-life over quantity-of-life (16). Research has described a shifting experience of what patients hope for as cure became less of a possibility (23).

In a U.S. study, neuro-oncology patients explored their beliefs about God's plans, grace, providence and forgiveness (21). In contrast, among patients in more secular Sweden, explicitly religious struggle was minimal, existential or spiritual struggle were present, and questions about "Why is this happening to me?" were prevalent (25). Studies also report fear of death and thoughts about the afterlife as a central R/S need for brain cancer patients $(21,23)$. One study reported that fear of being separated from family/ loved ones was the most distressing aspect of death (23).
Isolation is another commonly cited R/S need $(20,21,24,26)$ including physical separation from daily activities, growing existential distance from others, and shifting relationships (21). Importantly, patients distinguish between isolation and solitude. Isolation may be distressing, but times of solitude, peace, and quiet spiritual practices are important (24).

Contradictory R/S beliefs or thoughts have been reported (i.e., not being afraid of death and being afraid of death, not trusting God and only trusting God) $(21,23)$. Piderman and colleagues view this as a vacillation between consolation ("experience of comfort, reassurance, peace, gratitude hope or expectancy regarding a spiritual presence and/ or the afterlife"), and desolation ("spiritual struggle that may including pleading, bargaining, and feelings of abandonment or fear") [(21), p. 20 and 22]. They view these discrepancies as part of people's dynamic faith stories (21).

\section{Religious/spiritual coping}

Neuro-oncology patients and caregivers have described important R/S coping mechanisms including prayer $(17,21)$, talking to a religious authorities for moral and religious support (27), positive reframing $(21,28)$, having a quiet place to pray before surgery (27), reflecting on one's R/S with another person $(21,27)$, talking about death anxiety (23), re-evaluating life values (20), and other religious practices $(27,28)$. According to patients and caregivers, receiving information about how to access spiritual support services is also important. Information from a pamphlet was preferred and described as very important by a third of Canadian patients with brain metastases and their caregivers (18).

\section{Addressing religious/spiritual concerns}

Most studies report brain cancer patients and caregivers desire R/S care from healthcare providers, but often felt like these needs were overlooked or unaddressed $(16,23,25,28)$. One study reported that participants would desire R/S care, but not want their physicians to pray with them; they thought this placed "power" outside of the physician's hands (27). Healthcare providers appear to have varying understanding of neuro-oncology patients' and caregivers' R/S needs (28). Nurses claim that lack of time and knowledge are limiting factors for providing R/S care $(28,29)$; their R/S interventions are often limited to listening (29). The use of simple screening questions can help healthcare providers identify patients who may 


\begin{tabular}{|l|l|l|c|c|}
\hline Do you struggle with the loss of meaning and joy in your life? & Not at all & Somewhat & Quite a bit & A great deal \\
\hline Do you currently have what you would describe as religious or spiritual struggles? & Not at all & Somewhat & Quite a bit & A great deal \\
\hline
\end{tabular}

Figure 1 Spiritual screening questions. A response of 'Somewhat' or greater for either item indicates potential R/S struggle. Consider referral to a chaplain for spiritual assessment and spiritual care if indicated (31).

be experiencing $\mathrm{R} / \mathrm{S}$ distress and benefit from referral to a chaplain for spiritual assessment and spiritual care as indicated [(30); see Figure 1].

\section{Spiritual care for neuro-oncology patients and their caregivers: oncology chaplains' clinical experience}

Chaplains with experience caring for patients with brain cancer and their caregivers note the life-limiting nature of this illness; symptoms are challenging, and the side effects of treatment are often toxic (32). Patients frequently face rapid cognitive decline and neurologic impairment. The $\mathrm{R} / \mathrm{S}$ needs of patients are driven by these difficulties which threaten the core of patients' identity.

As their disease progresses, some patients who are religious or spiritual express feelings of disconnection and abandonment in their relationship with their higher power/God. Some question why they have brain cancer and not the treatable kind of cancer which their neighbor has. "Why me?" "Why now?" are common questions. Some have expressed guilt that they have done something to warrant God's punishment. Limited physical abilities affect participation in important religious activities such as attendance at church, temple, mosque, or other religious meetings. These can compromise patients' sense of purpose as they question why they are still on earth. As patients' memory diminishes and vision changes, they can no longer read comforting R/S texts and some patients report feeling their faith slipping through their fingers.

The spiritual concerns of patients with brain cancer are frequently driven by loss and grief, including loss of independence, control, identity, or purpose and meaning in life, as well as struggles with relationships and social support. Patients report no longer being able to engage in the basic elements of their work and family life as their disease progresses. Many have expressed frustration and embarrassment at not being able to perform activities of daily living. "I cannot brush my own teeth or dress myself ... I feel exposed as I no longer have any privacy." Patients struggle as they contemplate whether or not to have surgery as well as the outcomes of the surgery and other treatments. The question of quality-of-life comes up often. The thought of losing mobility/functionality is frightening for many brain cancer patients. "How much cognition will I lose before I die?" They have described seizures as a frightening experience associated with loss of independence, including not being able to drive or cook because having a seizure in the middle of these activities would be devastating.

Some patients report they do not recognize who they are anymore. Their sense of meaning and joy in life are diminished. As their diseases progress they worry about their new lifestyle, their functioning and ability to return to their job, sports, or hobbies. A future without important activities such as gardening, camping, fishing, or golfing seems meaningless. Patients fear losing the ability to make decisions for themselves as the disease causes problems with memory and judgment. Patients have also expressed regret about not having done enough in this life or completed their life's journey.

As patients recognize their loss of cognition and identity, they often express fears of what is to happen to them and what will become of the loved ones they will leave behind. Some have reported the hardest thing for them is not being able to take care of their family. "How will they cope without me?" "Who will take care of my spouse and children? I want to be sure they will be okay if something happens to me."

The loss of independence leads some patients to feel they have become a burden to their family. Being unable to provide leadership and stability to their family is a painful role reversal. In some cases, the patient has been the one who established and guided the family's R/S beliefs and practices. As brain cancer diminishes their cognitive abilities, their role as spiritual leader is diminished or ends completely. Patients fear that their families might lose faith in the face of the patient's disease and likely death. Patients have often asked what they can do to preserve their families' $\mathrm{R} / \mathrm{S}$ heritage. Patients grieve disconnection from future faith activities such as baptisms, marriages, and birth of grandkids, as well as their school and family activities. 
Table 1 Hear My Voice: selected themes and interview questions (35)

\begin{tabular}{ll}
\hline Theme & Selected interview questions \\
\hline Community & Have you ever been part of a religious or spiritual community? \\
& Has your connection changed in any way over your life time? \\
Contributions & Are there things you're proud of? How do you think your family, your community, your profession, your church are \\
better because of you? \\
Communication & Have you had periods in your life when you have faced questions about your faith or spiritual approach to life? \\
& Do you have spiritual guidance or wisdom that you'd like to share or reinforce one more time?
\end{tabular}

Some family members of patients with brain cancer must decrease their participation in R/S activities in order to care for their loved one. As the patients' condition deteriorates, family members sometimes ask, "Why is this happening to us?" or "Why is God doing this to my loved one?" Family members express fear of losing an elder who provided reassurance and guidance in times of family and spiritual crisis. Family members are willing to be with and support their loved ones, but they worry about when they will be able to go back to work. "We might lose the house if the bills are not paid." Family members also worry about future cognitive decline. "When they are no longer able to understand us, that will be hardest because we would be guessing what they are going through and how they are feeling."

Family members accompany patients as they wrestle with decisions about treatment but are afraid to make decisions that might lead to negative outcomes. "What if they are paralyzed? Life would have no meaning. I would not want my loved one to be a vegetable." Family members become very disillusioned when they do not have the information they need to understand the disease, the options available to help their loved ones, or access to these resources.

Spiritual care for neuro-oncology patient and their caregivers builds on core spiritual care activities. These include acknowledging and affirming the patient's and caregiver's emotions, identifying and addressing spiritual distress, and providing time for life review and meaning making. Chaplains also facilitate end-of-life discussions and advance care planning (33), advocate for patients and caregivers to have adequate information, and provide prayer and other R/S resources that will address patients' and caregiver's needs. Spiritual care may also include locating resources to fulfill specific R/S needs, as well as modalities such as guided imagery.

\section{Hear My Voice: a spiritual care intervention}

A spiritual life review intervention has been developed for patients with brain cancer and other advanced illnesses and their caregivers $(34,35)$. The intervention, "Hear My Voice", was designed to give patients voice before they lost their ability to communicate. Specifically, it allows patients to tell their story and leave a spiritual legacy for their loved ones. In the intervention patients describe core spiritual beliefs, practices, values, struggles, and life-learned wisdom (see Table 1). The interviews are transcribed, edited and returned to the patient as a spiritual legacy document that can be shared with loved ones. Piderman and colleagues have assessed the feasibility, acceptability and impact of this chaplain-led intervention (35-38). Findings from studies show increased positive religious coping, quality-of-life, and emotional and spiritual wellbeing (36-38). Patients and caregivers provide positive evaluations for the intervention.

\section{Conclusions}

Coping with illness presents significant R/S challenges for brain cancer patients and their caregivers. Current research about the role of R/S in coping for these patients is promising but limited. Spiritual care and a new spiritual care intervention, Hear My Voice, can play an important role in improving $\mathrm{R} / \mathrm{S}$ coping and quality-of-life. Additional research will advance our understanding of the role of R/ $\mathrm{S}$ in coping with brain cancer and ensure that patients and their caregivers receive the best spiritual care possible.

\section{Acknowledgments}

The authors express their appreciation to Kristen Schenk for her assistance in the preparation of the manuscript. 
Funding: None.

\section{Footnote}

Provenance and Peer Review: This article was commissioned by the Guest Editors (Jerome Graber, Hany Soliman) for the series "Palliative Care in Neuro-Oncology" published in Annals of Palliative Medicine. The article has undergone external peer review.

Peer Review File: Available at http://dx.doi.org/10.21037/ apm-20-813

Conflicts of Interest: All authors have completed the ICMJE uniform disclosure form (available at http://dx.doi. org/10.21037/apm-20-813). The series "Palliative Care in Neuro-Oncology" was commissioned by the editorial office without any funding or sponsorship. The authors have no other conflicts of interest to declare.

Ethical Statement: The authors are accountable for all aspects of the work in ensuring that questions related to the accuracy or integrity of any part of the work are appropriately investigated and resolved.

Open Access Statement: This is an Open Access article distributed in accordance with the Creative Commons Attribution-NonCommercial-NoDerivs 4.0 International License (CC BY-NC-ND 4.0), which permits the noncommercial replication and distribution of the article with the strict proviso that no changes or edits are made and the original work is properly cited (including links to both the formal publication through the relevant DOI and the license). See: https://creativecommons.org/licenses/by-nc-nd/4.0/.

\section{References}

1. Canada AL, Fitchett G. Religion/Spirituality and Cancer: A Brief Update of Selected Research. In: Holland JC, Breitbart WS, Butow PN, et al. editors. Psycho-Oncology. 3nd edition. New York: Oxford University Press, 2015:503-8.

2. Fitchett G, Canada AL. The role of religion/spirituality in coping with cancer: Evidence, assessment, and intervention. In: Holland JC, Breitbart WS, Jacobson PB, et al. editors. Psycho-Oncology. 2nd edition. New York: Oxford University Press, 2010:440-6.

3. Piderman KM, Kung S, Jenkins SM, et al. Respecting the spiritual side of advanced cancer care: a systematic review. Curr Oncol Rep 2015;17:6.

4. Peteet JR, Balboni MJ. Spirituality and religion in oncology. CA Cancer J Clin 2013;63:280-9.

5. Canada AL, Fitchett G, Murphy PE, et al. Racial/ethnic differences in spiritual well-being among cancer survivors. J Behav Med 2013;36:441-53.

6. Yates JS, Mustian KM, Morrow GR, et al. Prevalence of complementary and alternative medicine use in cancer patients during treatment. Support Care Cancer 2005;13:806-11.

7. Jim HS, Pustejovsky JE, Park CL, et al. Religion, spirituality, and physical health in cancer patients: a metaanalysis. Cancer 2015;121:3760-8.

8. Salsman JM, Pustejovsky JE, Jim HS, et al. A metaanalytic approach to examining the correlation between religion/spirituality and mental health in cancer. Cancer 2015;121:3769-78.

9. Sherman AC, Merluzzi TV, Pustejovsky JE, et al. A metaanalytic review of religious or spiritual involvement and social health among cancer patients. Cancer 2015;121:3779-88.

10. Delgado-Guay MO, Chisholm G, Williams J, et al. Frequency, intensity, and correlates of spiritual pain in advanced cancer patients assessed in a supportive/palliative care clinic. Palliat Support Care 2016;14:341-8.

11. Tarakeshwar N, Vanderwerker LC, Paulk E, et al. Religious coping is associated with quality of life of patients with advanced cancer. J Palliat Med 2006;9:646-57.

12. Thuné-Boyle IC, Stygall J, Keshtgar MR, et al. Religious coping strategies in patients diagnosed with breast cancer in the UK. Psychooncology 2011;20:771-82.

13. Best M, Butow P, Olver I. Do patients want doctors to talk about spirituality? A systematic literature review. Patient Educ Couns 2015;98:1320-8.

14. Schultz M, Lulav-Grinwald D, Bar-Sela G. Cultural differences in spiritual care: findings of an Israeli oncologic questionnaire examining patient interest in spiritual care. BMC Palliat Care 2014;13:19.

15. Astrow AB, Wexler A, Texeira K, et al. Is failure to meet spiritual needs associated with cancer patients' perceptions of quality of care and their satisfaction with care? J Clin Oncol 2007; 25: 5753-7.

16. Lipsman N, Skanda A, Kimmelman J, et al. The attitudes of brain cancer patients and their caregivers towards death and dying: a qualitative study. BMC Palliat Care 2007;6:7.

17. Randazzo DM, McSherry F, Herndon JE, et al. Complementary and integrative health interventions and 
their association with health-related quality of life in the primary brain tumor population. Complement Ther Clin Pract 2019;36:43-8.

18. Papadakos J, Agarwal A, Charow R, et al. Informational needs of brain metastases patients and their caregivers. Neurooncol Pract 2019;6:47-60.

19. Carmona-Bayonas A, Jimenez-Fonseca P, Vazquez Olmos $\mathrm{C}$, et al. Hyperreligiosity in malignant brain tumors: a case report and accompanying bibliographic review. Neurocase 2017;23:88-95.

20. Cavers D, Hacking B, Erridge SE, et al. Social, psychological and existential well-being in patients with glioma and their caregivers: a qualitative study. CMAJ 2012;184:E373-82.

21. Piderman KM, Eggington JS, Ingram C, et al. I'm still me: inspiration and instruction from individuals with brain cancer. J Health Care Chaplain 2017;23:15-33.

22. Newberry AG, Choi CW, Donovan HS, et al. Exploring spirituality in family caregivers of patients with primary malignant brain tumors across the disease trajectory. Onc Nurs Forum 2013;40:1-13.

23. Adelbratt S, Strang P. Death anxiety in brain tumour patients and their spouses. Palliat Med 2000;14:499-507.

24. Nixon A, Narayanasamy A. The spiritual needs of neurooncology patients from patients' perspective. J Clin Nurs 2010;19:2259-370.

25. Strang S, Strang P. Spiritual thoughts, coping and 'sense of coherence' in brain tumour patients and their spouses. Palliat Med 2001;15:127-34.

26. Giammalva GR, Iacopino DG, Azzarello G, et al. End-ofLife Care in High-Grade Glioma Patients. The Palliative and Supportive Perspective. Brain Sci 2018;8:125.

27. Ravishankar N, Bernstein M. Religion benefiting brain tumour patients: a qualitative study. J Relig Health 2014;53:1898-906.

28. Strang S, Strang P, Ternestedt BM. Existential support in brain tumour patients and their spouses. Support Care Cancer 2001;9:625-33.

Cite this article as: Sprik PJ, Tata B, Kelly B, Fitchett G. Religious/spiritual concerns of patients with brain cancer and their caregivers. Ann Palliat Med 2021;10(1):964-969. doi: 10.21037/apm-20-813
29. Nixon AV, Narayanasamy A, Penny V. An investigation into the spiritual needs of neuro-oncology patients from a nurse perspective. BMC Nurs 2013;12:2.

30. Bahraini S, Gifford W, Graham ID, et al. The accuracy of measures in screening adults for spiritual suffering in health care settings: A systematic review. Palliat Support Care 2020;18:89-102.

31. King SD, Fitchett G, Murphy PE, et al. Determining best methods to screen for religious/spiritual distress. Support Care Cancer 2017; 25:471-9.

32. Hammill K, Stewart CG, Kosic N, et al. Exploring the impact of brain cancer on people and their participation. Br J Occup Ther 2019;82:162-9.

33. Jeanne Wirpsa M, Emily Johnson R, Bieler J, et al. Interprofessional Models for Shared Decision Making: The Role of the Health Care Chaplain. J Health Care Chaplain 2019;25:20-44.

34. Piderman KM, Breitkopf CR, Jenkins SM, et al. A Chaplain-led Spiritual Life Review Pilot Study for Patients with Brain Cancers and Other Degenerative Neurologic Diseases. Rambam Maimonides Med J 2015;6:e0015.

35. Piderman KM, Breitkopf CR, Jenkins SM, et al. The feasibility and educational value of hear my voice, a chaplain-led spiritual life review process for patients with brain cancers and progressive neurologic conditions. J Cancer Educ 2015;30:209-12.

36. Piderman KM, Radecki Breitkopf C, Jenkins SM, et al. The impact of a spiritual legacy intervention in patients with brain cancers and other neurologic illnesses and their support persons. Psychooncology 2017;26:346-53.

37. Piderman KM, Radecki Breitkopf C, Jenkins SM, et al. Hearing and Heeding the Voices of those With Advanced Illnesses. J Palliat Care 2020. [Epub ahead of print]. doi: 10.1177/0825859720928623.

38. Sytsma TT, Bjork LB, Jenkins SM, et al. "Slowed Down but Not Stopped": A spiritual life review intervention in patients with neurodegenerative disease. J Pastoral Care Counsel 2020;74:108-14. 